\title{
Antibiotic Bone Cement and Ultraviolet Light Use in Total Knee Arthroplasty
}

\author{
John B. Meding, Kenneth E. Davis, Merrill A. Ritter \\ The Center for Hip and Knee Surgery, St. Francis Hospital Mooresville, Mooresville, Indiana, USA \\ Email: jmeding@me.com
}

How to cite this paper: Meding, J.B., Davis, K.E. and Ritter, M.A. (2016) Antibiotic Bone Cement and Ultraviolet Light Use in Total Knee Arthroplasty. Open Journal of Orthopedics, 6, 283-293.

http://dx.doi.org/10.4236/ojo.2016.69037

Received: August 13, 2016

Accepted: September 17, 2016

Published: September 20, 2016

Copyright $\odot 2016$ by authors and Scientific Research Publishing Inc. This work is licensed under the Creative Commons Attribution International License (CC BY 4.0).

http://creativecommons.org/licenses/by/4.0/

\begin{abstract}
Objective: The purpose of this study was to determine usefulness of antibiotic bone cement and UV light in primary Total Knee Arthroplasty (TKA). Patients and Methods: Between 1986 and 2008, 3105 TKAs were performed using $750 \mathrm{mg}$ of cefuroxime per bag of cement (Group 1), 7537 using cefuroxime and UV light (Group 2), and 4573 using UV light and gentamicin premixed (Group 3). Results: The primary infection rate was $0.57 \%$ (87 acute postoperative infections). Of these, $27(0.9 \%)$ were in Group 1, $44(0.6 \%)$ were in Group 2, and $16(0.35 \%)$ were in Group 3 ( $\mathrm{p}=0.0013)$. Kaplan-Meier survival in Groups 1 - 3 for reoperation for aseptic loosening of any component at 5 years was $0.9908,0.9927$, and 0.9959 , respectively $(\mathrm{p}=0.1315)$. Conclusion: Despite potential concerns mentioned in the literature, these results continue to support the use of antibiotic bone cement and UV lights during TKA.
\end{abstract}

\section{Keywords}

Antibiotic Bone Cement, Ultraviolet Light, Total Knee Arthroplasty, Infection, Complications

\section{Introduction}

The deep infection rate in the current era of total knee arthroplasty (TKA) may range from $0.5 \%$ to $1.6 \%$ [1]-[8]. Efforts to minimize the risk of infection after TKA include optimizing the patient's health status, using prophylactic antibiotics, aseptic skin preparations and drapes, laminar air flow, body exhaust systems, antibiotic irrigation, minimizing operating time and blood loss, and avoiding allogeneic blood transfusions [2] [9]. Although evidence suggests that using ultraviolet light (UVL) [10]-[19] and antibiotic-loaded bone cement (ALBC) [9] [20]-[32] may lead to lower infection rates after TKA, the routine use of these modalities in TKA remains controversial [2] [10] [11] 
[13] [18] [32]-[40]. Some authors have expressed concern about over-exposure to UVL during surgery [11] [13] [18] [36] [40]. Furthermore, the routine use of using ALBC has also been questioned because of the potential of antibiotic allergies [2] [37], the development of organism resistance [2] [35], compromising the mechanical strength of the bone cement [34] [39], and increased costs [37] [38].

The purpose of this study was to determine usefulness of UVL and ALBC during TKA in relationship to infection rates and the potential complications involved with the routine use of these two modalities.

\section{Method}

Between 1986 and 2008, 21,285 primary TKAs were performed at this institution. From this study base, 15,251 primary cemented TKAs were performed in 10,067 patients using antibiotic in the bone cement and had greater than 2 year follow up. Failing or infected knees at any follow up time were not excluded from the analysis. Table 1 lists the prostheses used in the study. From this group, 3105 TKAs were performed using 750 $\mathrm{mg}$ of cefuroxime (Lilly, Indianapolis, Indiana) per bag of cement (Group 1, 1986 to 1991) and no UVL in the operating room, 7537 TKAs were performed using $750 \mathrm{mg}$ of cefuroxime per bag of cement and UVL (Group 2, 1991 to 2003), and 4573 TKAs were performed using UVL and gentamicin premixed in the cement with either Palacose $\mathrm{R}$ (Zimmer, Warsaw, Indiana) or Cobalt HV (Biomet, Warsaw, Indiana) (Group 3, 20042008). The remaining 6034 TKAs were performed over the twenty-two year span of this study with or without UVL and were either uncemented or hybrid TKAs or TKAs performed in patients with a cephalosporin and/or penicillin allergy. Thus, this heterogeneous group of patients was not included per exclusion criteria. Table 2 lists the demographic data for the three groups. All patients received either cefazolin, cefuroxime, or vancomycin (Lilly, Indianapolis, Indiana) pre-operatively and for twenty-four to forty-eight hours post-operatively. Cefazolin and cefuroxime was infused with sixty minutes of the start of the operation. Because vancomycin is given over one hour at our institution, as per protocol, it was started ninety minutes to two hours before the surgery

Table 1. Prosthesis data.

\begin{tabular}{cc}
\hline Prosthesis & $\%$ (number TKAs) \\
\hline IB-II* & $0.9 \%(123)$ \\
IB-CCK & $0.1 \%(15)$ \\
Legacy CR & $2 \%(305)$ \\
Legacy PS & $4.8 \%(731)$ \\
AGC CR & $69.5 \%(10,605)$ \\
AGC PS & $0.3 \%(51)$ \\
Vanguard CR & $10 \%(1528)$ \\
Vanguard PS & $12.4 \%(1893)$ \\
\hline
\end{tabular}

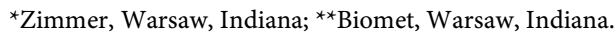


Table 2. Demographic data.

\begin{tabular}{|c|c|c|c|c|}
\hline & Group 1 & Group 2 & Group 3 & $\mathrm{p}$-value \\
\hline \# TKAs & 3105 & 7537 & 4573 & - \\
\hline Diagnosis (\%) & & & & $<0.0001$ \\
\hline Osteoarthritis & $86.1 \%$ & $97.8 \%$ & $99.6 \%$ & \\
\hline Osteonecrosis & $10.4 \%$ & $1.6 \%$ & $0.3 \%$ & \\
\hline Rheumatoid arthritis & $3.5 \%$ & $0.5 \%$ & $0.1 \%$ & \\
\hline Other & - & $0.1 \%$ & - & \\
\hline Gender (\%) & & & & 0.7139 \\
\hline Male & $39 \%$ & $40 \%$ & $37 \%$ & \\
\hline Female & $61 \%$ & $60 \%$ & $63 \%$ & \\
\hline Age (years) & & & & 0.0006 \\
\hline Average & 67.9 & 69.0 & 66.2 & \\
\hline Range & $19-91$ & $19-93$ & $30-91$ & \\
\hline sd. & 9.4 & 9.3 & 9.5 & \\
\hline BMI $\left(\mathrm{kg} / \mathrm{m}^{2}\right)$ & & & & $<0.0001$ \\
\hline Average & 27.8 & 31.0 & 33.7 & \\
\hline Range & $15-64$ & $15-64$ & $13-61$ & \\
\hline sd. & 5.9 & 2.9 & 6.7 & \\
\hline Follow-up (years) & & & & - \\
\hline Average & 12.8 & 7.6 & 3.6 & \\
\hline Range & $0-28$ & $0-19$ & $0-7$ & \\
\hline sd. & 5.9 & 3.7 & 1.0 & \\
\hline
\end{tabular}

start time. In all cases the skin preparation included an alcohol prep and adhesive drape. Jet lavage with gentamycin irrigation and suction drying prior to cementation was used in all cases.

Acute post-op infection was defined as any deep (periprosthetic) infection identified within the first six months after TKA having a positive intra-articular culture obtained from aspiration or at the time of irrigation and debridement. These included acute $(<$ four weeks after TKA) and late chronic ( $>$ four weeks after TKA) [41] [42].

Statistical power analysis allowed for the ability to detect a $0.2 \%$ difference in the infection rate between the three groups (beta 0.195, alpha 0.05). Continuous variables were evaluated with analysis of variance (ANOVA) one-way across three groups, and categorical variables using the chi-square statistic. Cox regression was used to determine the hazard ratio/risk of infection between the three groups. We reported the p-value of the Jonckheere-Terpstra test [43] for the decrease in infection rate between groups since study groups correspond to specific operation date ranges and we achieved greater statistical power by testing for a monotonically decreasing trend for a relatively 
infrequent event (infection). Survivorship was determined by the Kaplan-Meier method [44] with failure defined as aseptic loosening of any component for any reason. All data was collected prospectively and then retrospectively queried in the computer database.

\section{Results}

The primary infection rate for the entire study group (15,251 TKAs) was $0.57 \%$ ( 87 acute postoperative infections). There were twenty-seven deep infections $(0.9 \%)$ in Group 1, forty-four deep infections (0.6\%) in Group 2, and sixteen deep infections $(0.35 \%)$ in Group $3(\mathrm{p}=0.0013)$. Within group 3, there was no statistical difference between the numbers of deep infections using Palacos $\mathrm{R}$ with gentamyicn $(9$ cases, $0.38 \%$ ) or Cobalt HV with gentamycin (7 cases, $0.32 \%)(\mathrm{p}=0.4633)$. Table 3 lists the offending organisms according to each group including antibiotic resistance.

With the lowest infection rate $(0.35 \%)$ found in Group 3 patients (hazard ratio (HR) $=1.0$ ), Cox regression analysis demonstrated that Group 1 patients had a 2.3 times the risk of deep infection when compared to Group 3. Whereas, Group 2 patients had a 1.3 times the risk of infection when compared to Group 3. The full Cox model included age over $70(\mathrm{HR}=0.46, \mathrm{p}=0.0434)$ and $\mathrm{BMI}$ over $40(\mathrm{HR}=2.8, \mathrm{p}=0.0127)$.

Kaplan-Meier survivorship in Groups 1 - 3 for reoperation for aseptic loosening of any component at five years $(95 \% \mathrm{CI})$ was $0.9908(0.9854,0.9942), 0.9927(0.9891$, 0.9952 ), and $0.9959(0.9934,0.9975)$, respectively (Wilcoxon, $\mathrm{p}=0.1315)$ (Figure 1 ).

Table 3. Organisms according to group percentage infected in group, infection count of group count organism, count, organism percentage of those infected in group.

\begin{tabular}{|c|c|c|}
\hline $\begin{array}{l}\text { Group } 1(0.9 \% \text { infected }) \\
\quad(n=27 \text { of } 3105)\end{array}$ & $\begin{array}{l}\text { Group } 2 \text { (0.6\% infected) } \\
\quad(\mathrm{n}=44 \text { of } 7537)\end{array}$ & $\begin{array}{l}\text { Group } 3 \text { ( } 0.3 \% \text { infected }) \\
\quad(n=16 \text { of } 4573)\end{array}$ \\
\hline S. aureus [9] (33\%) & S. aureus $[20](45 \%)$ & S. aureus $[8](50 \%)$ \\
\hline S. epiermidis [6] (22\%) & $\dagger S$. aureus $[1](2 \%)$ & ${ }^{*}$ S. aureus $[2](13 \%)$ \\
\hline${ }^{\star}$ S. epidermidis $[1](4 \%)$ & S. epidermidis [5] (11\%) & S. epidermidis [2] (13\%) \\
\hline${ }^{*} P$. aeroginous $[4](15 \%)$ & ${ }^{*}$ S. epidermidis $[1](2 \%)$ & Corynebacteria [1] (6\%) \\
\hline Group D Entercoccus [3] (11\%) & ${ }^{*} P$. aeroginous $[3](7 \%)$ & Peptostreptococcus [1] (6\%) \\
\hline Strep.pyogenes [2] (7\%) & Group B Streptococcus [4] (9\%) & Enetrococcus faecalis [1] (6\%) \\
\hline Klebsiella oxytoca [1] (4\%) & Strep. pyogenes [2] (5\%) & Sterp. viridans $[1](6 \%)$ \\
\hline \multirow[t]{9}{*}{ Enterbacter cloacae [1] (4\%) } & Corynebacteria [1] (2\%) & \\
\hline & Strep. viridans [2] (5\%) & \\
\hline & Group D Entercoccus [1] (2\%) & \\
\hline & Klebsiella oxytoca $[1](2 \%)$ & \\
\hline & Enterbacter cloacae [1] (2\%) & \\
\hline & $\dagger$ Serratia marcescens [1] (2\%) & \\
\hline & Pasturella multocida [1] (2\%) & \\
\hline & E. coli $[1](2 \%)$ & \\
\hline & Staph. lugdunensis [1] (2\%) & \\
\hline
\end{tabular}

${ }^{*}$ Methicillin/cefazolin resistant (sensitive to cefuroxime); ${ }^{*}$ Cefazolin resistant (sensitive to cefuroxime); $†$ Resistant to cefuroxime. 
5-Year Aseptic Loosening between Infection Groups Kaplan-Meier

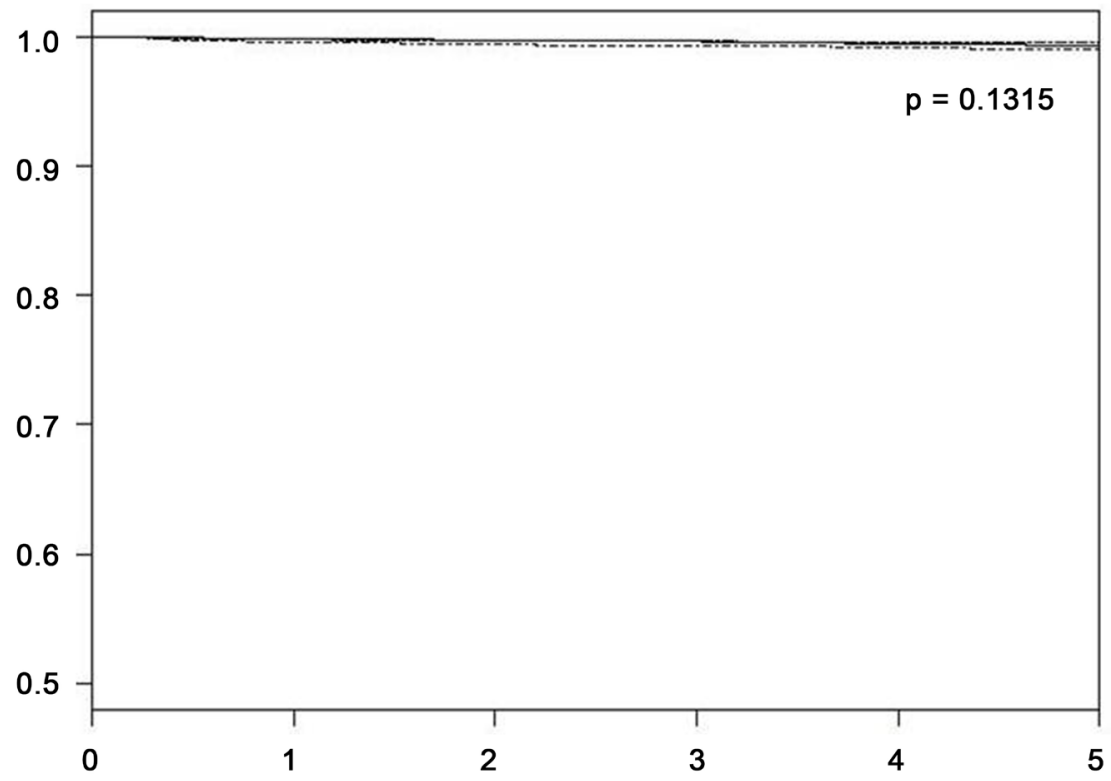

Figure 1. 5-year Kaplan Meier survivorship with failure defined as aseptic loosening for any reason.

\section{Discussion}

Joint arthroplasty surgeons understand the need to constantly evaluate ways of preventing deep infection before, during, and after TKA. Preventative methods that were consistent and used in all patients throughout the years of this study included the use of prophylactic antibiotics, skin preparation and adhesive drapes, laminar air-flow, and the use of antibiotic irrigation. Obviously, the variables that were less consistent included operating room time, intra-operative blood loss, operating room traffic, and the use of allogeneic blood. The two methods under consideration in this study were the use of UVL and ALBC.

Numerous studies have reported on the efficacy of UVL in reducing the number of colony forming units of bacteria in the operating room [10]-[19]. UVL are extremely cost-effective when compared to creating an ultra clean air enclosure [11] [18]. In a previous report from our institution, Ritter et al. reported on over 6000 TKAs and total hip replacements (THAs) and noted an over threefold risk of deep infection when UVL were not used [18]. In the present study of TKAs, the risk of infection was almost doubled ( 1.3 to 2.3 times the risk) when UVL were not used. Both Groups 1 and 2 used cefuroxime in the bone cement. The safety of the operating room personnel has been called into question, however, with the use of UVL [11] [13] [18] [36] [40]. In fact, Evans [13] reported that, in spite of using protective garments and eye shields, operating room personnel were exposed to between six and twenty-eight times the maximal limit as established by the National Institute of Occupational and Safety Health. Clearly, skin and eye protection and employee education diminish the danger of overexposure [16] [18]. 
Similarly, ALBC has been found in a multitude of studies to be at least as good as systemic antibiotics in preventing deep infection after total joint arthroplasty [9] [22][31], the use of ALBC is most impressive when reviewing registry data as well. In a review of 10,905 cemented THAs from the Norwegian registry, the lowest infection rates were noted with the use of systemic antibiotics and ALBC. [26] Malchau et al. [30] reported on 92,675 THAs and noted a lower risk of infection with the use of operating room ventilation and ALBC. Furthermore, the lowest revision rates were seen in hips when gentamycin ALBC was used [30]. While we did not specifically compare TKAs with and without ALBC, we did find a $30 \%$ increase in the infection rate when cefuroxime was used instead of gentamycin (1.3 times the risk in Group 2 compared to Group 3). It should be noted, however, that in the United States, ALBC is only FDA approved for the second stage of a re-implanted joint arthroplasty when the infection has been cured.

Although Hannsen et al. [2] and Jiranek et al. [37] raised concern over the development of allergies with using ALBC it should be noted that we identified no cases of an allergic response in our database. Clearly, not all patents were specifically allergy tested however. We believe this specific concern is unfounded. This study did not include patients who did not receive ALBC because of pre-existing allergy concerns. Further, we did not specifically evaluate ALBC toxicity [37] or cost [37] [38]. Heck et al. [34] and Postack et al. [39] raised concern over the mechanical consequences of using ALBC with respect to loosening. We did not specifically, compare survivorship with and without ALBC as nearly every case at our institution, except those patients with a document antibiotic allergy prior to TKA, receives ALBC. However, we noted no difference in survivorship between any of the three groups studied, including a 99\% TKA survivorship at five years in all three groups with respect to aseptic loosening of any component.

Authors have also expressed concern over the development of drug resistance using ALBC [2] [35]. In the present study, six different drug resistant organisms were identified. One case of methicillin-resistant $S$. epidermidis (each) was found in Group 1 and 2. In both cases the organism was sensitive to cefuroxime. One case of a methicillin-resistant $S$. aureus was found in Group 3. Similarly, this organism was sensitive to cefuroxime. One case (each) of cefazolin-resistant $P$. aeroginous was identified in Groups 1 and Groups 2. In both cases the organism was sensitive to cefuroxime. There was one S. aureus and one Serratia marcescens infection (both in Group 2) that were resistant to cefuroxime. Finally there was one Peptostreptococcus infection (Group 3) that could be considered resistant to gentamycin. However, one would not use an amino glycoside to treat this organism in the first place. Thus, only two possible cases of an organism resistant infection due to the use of ALBC could be considered to have occurred in this study.

Patients in Group 2 were statistically older that those in Group 1 and Group 3. This difference was less than three years, however. Also, the average BMI was lower in Group 1 compared to Groups 2 and Groups 3. We believe this difference is a reflection 
of the expanding indications for TKA in the later years of this study. Nevertheless, the infection rate was actually higher in Group 1.

There are potential weaknesses found in this study. The surgical technique was not entirely uniform during the years of this study including the use of body exhaust systems and prosthesis selection. These concerns may be offset, in part, due to the relatively large patient sample in this study. Second, patient's co-morbid medical conditions (including diabetes, vascular disease, and smoking history) were not specifically evaluated. The increase risk of periprosthetic infection in patients with these co morbid conditions (including rheumatoid arthritis) is well-established [2]-[4] [6] [7] [45]. We recognize that the groups in this report are heterogeneous in this regard and that the statistical differences observed in this study may be accounted for by factors other than ABLC and UVL. For example, Group 1 had a greater percentage of rheumatoid arthritis patients that the other two groups. Yet, it is our impression that during the later years of this study our indications for TKA broadened to include patients with more severe medical conditions. Third, we did not consider culture-negative deep infections in this study. However, the deep infection rate in this study $(0.57 \%)$ was similar to a previous report from our institution that included THA and TKA with a deep infection rate of $0.53 \%[45]$.

Fourth, a single surgeon, well versed, improved his or her surgical skills over time, including the handling of soft tissues and the improvement of his/her peri-operative routine. These factors need to be considered over the twenty-two year span of this study. However, between 1986 and 1991, three surgeons all with at least ten years of joint arthroplasty experience were involved. Three fellowship-trained arthroplasty surgeons were added, one each, in 1992, 1998, and 2003. Thus, if surgeon experience and efficiency were factors in this study, one would expect the infection rate to increase. Over the three time intervals in the present investigation, the infection rate actually decreased with time. Fifth, the operating room team, ventilation system, staff, and traffic are other important variables than may influence infection rates after TKA. Other factors not included in this study include operative time, transfusion rate, and tourniquet time. It is unclear as to what effect, if any, these factors had on infection rates based on the present review. Finally, we did not feel any exclusion criteria detracted from outcome of the study as those surgeries (uncemented prosthesis, etc.) were somewhat beyond the scope of this study.

Cefuroxime is prepared as a fine white powder and mixes well with bone cement. It was chosen at our institution because of availability and satisfactory thermal stability to allow adequate elution of antibiotic into the joint fluid [4] [22] [32] [38] [46]. Antibiotic in liquid form may dilute the catalyst that is needed for curing of the cement and, therefore, adversely affects its mechanical properties [22]. With regards to cefuroxime, concentrations up to two grams of antibiotic powder per forty-gram package of cement does not substantially change the static tensile or compressive strength of the cement [4] [22]. In addition, cefuroxime has a broad spectrum of coverage, although some coagulase negative Staphylococcus are resistant to cefuroxime. Gentamycin premix, on 
the other hand, has been used at our institution since 2004 because of this concern including enterococcus resistance.

\section{Conclusion}

Based on the results of this study, we routinely use ALBC and UV lights during TKA. We found little evidence to support the adverse effects of using either of these modalities during TKA.

\section{References}

[1] Chesney, D., Sales, J., Elton, R. and Brenkel, I.J. (2008) Infection after Knee Arthroplasty: A Prospective Study of 1509 Cases. The Journal of Arthroplasty, 23, 355-359.

[2] Hanssen, A.D., Osmon, D.R. and Nelson, C.L. (1996) Prevention of Deep Periprosthetic Joint Infection. Journal of Bone and Joint Surgery, 78, 458-471.

[3] Hanssen, A.D. and Rand, J.A. (1998) Evaluation and Treatment of Infection at the Site of a Total Hip or Knee Arthroplasty. Journal of Bone and Joint Surgery, 80, 910-922.

[4] Meding, J.B., Reddleman, K., Keating, M.E., Klay, A., Ritter, M.A., Faris, P.M. and Berend, M.E. (2003) Total Knee Replacement in Patients with Diabetes Mellitus. Clinical Orthopaedics and Related Research, 416, 208-216. http://dx.doi.org/10.1097/01.blo.0000093002.90435.56

[5] Mahomed, N.N., Barrett, J.A., Katz, J.N., Phillips, C.B., Losina, E., Lew, R.A., Guadagnoli, E., Harris, W.H., Poss, R. and Baron, J.A. (2003) Rates and Outcomes of Primary and Revision Total Hip Replacement in the United States Medicare Population. Journal of Bone and Joint Surgery, 85, 27-32.

[6] Pulido, L., Ghanem, E., Joshi, A., Purtill, J.J and Parvizi, J. (2008) Periprosthetic Joint Infection: The Incidence, Timing, and Predisposing Factors. Clinical Orthopaedics and Related Research, 466, 1710-1715. http://dx.doi.org/10.1007/s11999-008-0209-4

[7] Saleh, K., Olson, M., Resig, S., Bershadsky, B., Kuskowski, M., Gioe, T., Robinson, H., Schmidt, R. and McElfresh, E. (2002) Predictors of Wound Infection in Hip and Knee Joint Replacement: Results from a 20 Year Surveillance Program. Journal of Orthopaedic Research, 20, 506-515. http://dx.doi.org/10.1016/S0736-0266(01)00153-X

[8] Spangehl, M.J., Younger, A.S.E., Masri, B.A. and Duncan, C.P. (1997) Diagnosis of Infection Following Total Hip Arthroplasty. Journal of Bone and Joint Surgery, 79, 1578-1588.

[9] Matar, W.Y., Jafari, S.M., Restrepo, C., Austin, M., Purtill, J.J. and Parvizi, J. (2010) Preventing Infection in Total Joint Arthroplasty. Journal of Bone and Joint Surgery, 92, 36-46. http://dx.doi.org/10.2106/JBJS.J.01046

[10] Berg, M. and Bergman, B.R. (1991) Ultraviolet Radiation Compared to an Ultra-Clean Air Enclosure. Comparison of Air Bacteria Counts in Operating Rooms. Journal of Bone and Joint Surgery (British Volume), 73, 811-815.

[11] Berg-Périer, M., Cederblad, A. and Persson, U. (1992) Ultraviolet Radiation and Ultraclean Air Enclosures in Operating Rooms. UV-Protection, Economy, and Comfort. The Journal of Arthroplasty, 7, 457-463.

[12] Carlsson, A.S., Nilsson, B., Walder, M.H. and Osterberg, K. (1986) Ultraviolet Radiation and Air Contamination during Total Hip Replacement. Journal of Hospital Infection, 7, 176-184.

[13] Evans, R.P. (2011) Current Concepts for Clean Air and Total Joint Arthroplasty: Laminar Airflow and Ultraviolet Radiation: A Systematic Review. Clinical Orthopaedics and Related 
Research, 469, 945-953.

[14] Fletcher, N., Sofianos, D., Berkes, M.B. and Obremskey, W.T. (2007) Prevention of Perioperative Infection. Journal of Bone and Joint Surgery, 89, 1605-16018.

[15] Goldner, J.L. and Allen Jr., B.L. (1973) Ultraviolet Light in Orthopedic Operating Rooms at Duke University. Thirty-Five Years' Experience, 1937-1973. Clinical Orthopaedics and Related Research, 96, 195-205.

[16] Lidwell, O.M. (1994) Ultraviolet Radiation and the Control of Airborne Contamination in the Operating Room. Journal of Hospital Infection, 28, 245-248. http://dx.doi.org/10.1016/0195-6701(94)90088-4

[17] Moggio, M., Goldner, J.L., McCollum, D.E. and Beissinger, S.F. (1979) Wound Infections in Patients Undergoing Total Hip Arthroplasty. Ultraviolet Light for the Control of Airborne Bacteria. Archives of Surgery, 114, 815-823. http://dx.doi.org/10.1001/archsurg.1979.01370310057011

[18] Ritter, M.A., Olberding, E.M. and Malinzak, R.A. (2007) Ultraviolet Lighting during Orthopaedic Surgery and the Rate of Infection. Journal of Bone and Joint Surgery, 89, 19351940. http://dx.doi.org/10.2106/JBJS.F.01037

[19] Taylor, G.J., Bannister, G.C. and Leeming, J.P. (1995) Wound Disinfection with Ultraviolet Radiation. Journal of Hospital Infection, 30, 85-93. http://dx.doi.org/10.1016/0195-6701(95)90148-5

[20] Buchholz, H.W., Engelbrecht, E., Rotterger, J. and Siegel, A. (1976) Erkenntnisse nach Wechsel von über 400 infizierten Hutrendoprothesen. Orthop Praxis, 12, 1117-1121.

[21] Buchholz, H.W., Elson, R.A. and Heinert, K. (1984) Antibiotic-Loaded Acrylic Cement: Current Concepts. Clinical Orthopaedics and Related Research, 190, 96-108. http://dx.doi.org/10.1097/00003086-198411000-00014

[22] Chiu, F.Y., Chen, C.M., Lin, C.F. and Lo, W.H. (2002) Cefuroxime-Impregnated Cement in Primary Total Knee Arthroplasty: A Prospective, Randomized Study of Three Hundred and Forty Knees. Journal of Bone and Joint Surgery, 84-A, 759-762.

[23] Cummins, J.S., Tomek, I.M., Kantor, S.R., Furnes, O., Engesaeter, L.B. and Finlayson, S.R. (2009) Cost-Effectiveness of Antibiotic-Impregnated Bone Cement Used in Primary Total Hip Arthroplasty. Journal of Bone and Joint Surgery, 91, 634-641. http://dx.doi.org/10.2106/JBJS.G.01029

[24] Dunbar, M.J. (2009) Antibiotic Bone Cements: Their Use in Routine Primary Total Joint Arthroplasty Is Justified. Orthopedics, 32, 660. http://dx.doi.org/10.3928/01477447-20090728-20

[25] Engesaeter, L.B., Lie, S.A., Espehaug, B., Furnes, O., Vollset, S.E. and Havelin, L.I. (2003) Antibiotic Prophylaxis in Total Hip Arthroplasty: Effects of Antibiotic Prophylaxis Systemically and in Bone Cement on the Revision Rate of 22,170 Primary Hip Replacements Followed 0-14 Years in the Norwegian Arthroplasty Register. Acta Orthopaedica Scandinavica, 74, 644-651. http://dx.doi.org/10.1080/00016470310018135

[26] Espehaug, B., Engesaeter, L.B., Vollset, S.E., Havelin, L.I. and Langeland, N. (1997) Antibiotic Prophylaxis in Total Hip Arthroplasty. Review of 10,905 Primary Cemented Total Hip Replacements Reported to the Norwegian Arthroplasty Register, 1987 to 1995. Journal of Bone and Joint Surgery, 79, 590-595. http://dx.doi.org/10.1302/0301-620X.79B4.7420

[27] Josefsson, G., Lindberg, L. and Wiklander, B. (1981) Systemic Antibiotics and Gentamicin-Containing Bone Cement in the Prophylaxis of Postoperative Infections in Total Hip Arthroplasty. Clinical Orthopaedics and Related Research, 159, 194-200.

[28] Josefsson, G., Gudmundsson, G., Kolmert, L. and Wijkström, S. (1990) Prophylaxis with 
Systemic Antibiotics versus Gentamicin Bone Cement in Total Hip Arthroplasty. A FiveYear Survey of 1688 Hips. Clinical Orthopaedics and Related Research, 253, 173-178.

[29] Lynch, M., Esser, M.P., Shelley, P. and Wroblewski, B.M. (1987) Deep Infection in Charnley Low-Friction Arthroplasty. Comparison of Plain and Gentamicin-Loaded Cement. Journal of Bone and Joint Surgery, 69, 355-360.

[30] Malchau, H., Herberts, P. and Ahnfelt, L. (1993) Prognosis of Total Hip Replacement in Sweden. Follow-Up of 92,675 Operations Performed 1978-1990. Acta Orthopaedica Scandinavica, 64, 497-506. http://dx.doi.org/10.3109/17453679308993679

[31] Parvizi, J., Saleh, K.J., Ragland, P.S., Pour, A.E. and Mont, M.A. (2008) Efficacy of Antibiotic-Impregnated Cement in Total Hip Replacement. Acta Orthopaedica, 79, 335-341. http://dx.doi.org/10.1080/17453670710015229

[32] Bourne, R.B. (2004) Prophylactic Use of Antibiotic Bone Cement: An Emerging Standard-In the Affirmative. Journal of Arthroplasty, 19, 69-72. http://dx.doi.org/10.1016/j.arth.2004.03.005

[33] Hanssen, A.D. (2004) Prophylactic Use of Antibiotic Bone Cement: An Emerging Standard-In Opposition. Journal of Arthroplasty, 19, 73-77. http://dx.doi.org/10.1016/j.arth.2004.04.006

[34] Heck, D., Rosenberg, A., Schink-Ascani, M., Garbus, S. and Kiewitt, T. (1995) Use of Antibiotic-Impregnated Cement during Hip and Knee Arthroplasty in the United States. Journal of Arthroplasty, 10, 470-475. http://dx.doi.org/10.1016/S0883-5403(05)80148-2

[35] Hope, P.G., Kristinsson, K.G., Norman, P. and Elson, R.A. (1989) Deep Infection of Cemented Total Hip Arthroplasties Caused by Coagulase-Negative Staphylococci. Journal of Bone and Joint Surgery, 71, 851-855.

[36] Howard, J.L. and Hanssen, A.D. (2007) Principles of a Clean Operating Room Environment. Journal of Arthroplasty, 22, 6-11. http://dx.doi.org/10.1016/j.arth.2007.05.013

[37] Jiranek, W.A., Hanssen, A.D. and Greenwald, A.S. (2006) Antibiotic-Loaded Bone Cement for Infection Prophylaxis in Total Joint Replacement. Journal of Bone and Joint Surgery, 88, 2487-2500. http://dx.doi.org/10.2106/JBJS.E.01126

[38] Joseph, T.N., Chen, A.L. and Di Cesare, P.E. (2003) Use of Antibiotic-Impregnated Cement in Total Joint Arthroplasty. Journal of the American Academy of Orthopaedic Surgeons, 11, 38-47. http://dx.doi.org/10.5435/00124635-200301000-00006

[39] Postak, P.D. and Greenwald, A.S. (2006) The Influence of Antibiotics on the Fatigue Life of Acrylic Bone Cement. Journal of Bone and Joint Surgery, 88, 148-155. http://dx.doi.org/10.2106/JBJS.F.00586

[40] Sehulster, L. and Chinn, R.Y. (2003) Guidelines for Environmental Infection Control in Health-Care Facilities. Recommendations of CDC and the Healthcare Infection Control Practices Advisory Committee (HICPAC). MMWR Recommendations and Reports, 52, 142.

[41] Segawa, H., Tsukayama, D.T., Kyle, R.F., Becker, D.A. and Gustilo, R.B. (1999) Infection after Total Knee Arthroplasty. A Retrospective Study of the Treatment of Eighty-One Infections. Journal of Bone and Joint Surgery, 81-A, 1434-1445.

[42] Tsukayama, D.T., Goldberg, V.M. and Kyle, R. (2003) Diagnosis and Management of Infection after Total Knee Arthroplasty. Journal of Bone and Joint Surgery, 85, S75-S80.

[43] Jonckheere, A.R. (1954) A Distribution-Free K-Sample Test Again Ordered Alternatives. Biometrika, 41, 133-145. http://dx.doi.org/10.1093/biomet/41.1-2.133

[44] Kaplan, E.L. and Meier, P. (1958) Nonparametric Estimation from Incomplete Observations. Journal of the American Statistical Association, 53, 457-481. 
http://dx.doi.org/10.1080/01621459.1958.10501452

[45] Malinzak, R.A., Ritter, M.A., Berend, M.E., Meding, J.B., Olberding, E.M., Davis, K.E. (2009) Morbid Obese, Diabetic, Younger, and Unilateral Joint Arthropasty Patients Have Elevated Total Joint Arthroplasty Infection Rates. Journal of Arthroplasty, 24, 84-88.

http://dx.doi.org/10.1016/j.arth.2009.05.016

[46] Hughes, S., Field, C.A., Kennedy, M.R. and Dash, C.H. (1979) Cephalosporin in BoneCement: Studies in Vitro and in Vivo. Journal of Bone and Joint Surgery, 61, 96-100.

\section{Submit or recommend next manuscript to SCIRP and we will provide best service} for you:

Accepting pre-submission inquiries through Email, Facebook, LinkedIn, Twitter, etc. A wide selection of journals (inclusive of 9 subjects, more than 200 journals)

Providing 24-hour high-quality service

User-friendly online submission system

Fair and swift peer-review system

Efficient typesetting and proofreading procedure

Display of the result of downloads and visits, as well as the number of cited articles

Maximum dissemination of your research work

Submit your manuscript at: http://papersubmission.scirp.org/

Or contact ojo@scirp.org 